\title{
Lung function in adults born prematurely with bronchopulmonary dysplasia
}

\author{
I-Ling Chen ${ }^{1} \wedge$, Hsiu-Lin Chen ${ }^{1,2} \wedge$ \\ ${ }^{1}$ Department of Respiratory Therapy, College of Medicine, Kaohsiung Medical University, Kaohsiung; ${ }^{2}$ Division of Neonatology, Department of \\ Pediatrics, Kaohsiung Medical University Hospital, Kaohsiung \\ Correspondence to: Hsiu-Lin Chen. Department of Respiratory Therapy, College of Medicine, Kaohsiung Medical University, Kaohsiung; Division of \\ Neonatology, Department of Pediatrics, Kaohsiung Medical University Hospital, Kaohsiung. Email: ch840062@kmu.edu.tw. \\ Provenance and Peer Review: This article was commissioned by the editorial office, Translational Pediatrics. This article did not undergo external peer \\ review. \\ Comment on: Yang J, Kingsford RA, Horwood J, et al. Lung Function of Adults Born at Very Low Birth Weight. Pediatrics 2020;145:e20192359.
}

Submitted Apr 07, 2020. Accepted for publication Apr 28, 2020.

doi: $10.21037 /$ tp-20-116

View this article at: http://dx.doi.org/10.21037/tp-20-116

Bronchopulmonary dysplasia (BPD), which interferes pulmonary vascular and alveolar development especially in preterm infants, usually results from hyperopia, degree of prematurity, prolonged mechanical ventilation and other antenatal risk factors. The diagnostic criteria for BPD are persistent oxygen dependency up to 28 days of life and/or a need for supplemental oxygen at the postmenstrual age of 36 weeks (1).

Infants with BPD may not only suffer respiratory-related problems such as respiratory distress symptoms, increased bronchial secretion and repeated lower tract infection, but also develop feeding problem and delayed growth. Systemic hypertension, poor neurodevelopmental outcome, pulmonary hypertension and left ventricular hypertrophy and left ventricular dysfunction are complications attributed to BPD (2). BPD survivors may also be at a greater susceptibility of developing compromised lung defence, asthma-like symptoms and exercise intolerance for long term (3).

The study by Yang et al. (4) in the issue of Paediatrics conducted a national cohort study to investigate the alterations in lung function (i.e., spirometry, plethysmographic lung volumes, diffusing capacity and single-breath nitrogen washout). They described those very low birth weight (VLBW) survivors aged 26-30 years (born in 1986) in New Zealand suffered higher incidence of airflow obstruction, gas trapping, reduced gas exchange and ventilator inhomogeneity. Moreover, BPD (defined as receiving supplementary oxygen at 36 weeks' postmenstrual age) worsened the scenario. These findings suggested BPD have long-term effects on lung function and raise awareness that late pulmonary sequelae might lead to higher occurrence of pulmonary diseases in future years.

Indeed, a considerable body of data has revealed that BPD might contribute to the deviations in lung function. Preterm infants with BPD had diminished functional residual capacity (FRC) depending on severity of the disease $(5,6)$ and compliance $(6)$. Extremely preterm infants with BPD at a post-conceptional age of 44 weeks had airway obstruction measured by lower peak tidal expiratory flow as a proportion of expiratory time (TPTEF/TE ratio) reflected the increasing severity of BPD (7). Infants with BPD at the age of $36-42$ postconceptional weeks had reduced respiratory functions demonstrated by higher incidence of concave tidal breathing flow-volume loop (TBFVL) and an increased respiratory rate (8). Furthermore, survivors with BPD had abnormal airway patency in the first year (9) and third year (10) of life measured by decreasing maximal flow at FRC (V'maxFRC). VLBW preterm infants with BPD also had lower forced vital capacity (FVC) (11), forced

^, I-Ling Chen: ORCID: 0000-0002-6377-4332; Hsiu-Lin Chen: ORCID: 0000-0002-0565-4631

(c) Translational Pediatrics. All rights reserved. 
expiratory flow at $50 \%$ of vital capacity (FEF50) (11), forced expiratory volume in one second $\left(\mathrm{FEV}_{1}\right)(11-13)$, and forced mid-expiratory flow (FEF25-75) $(12,13)$ but increased residual volume/total lung capacity (RV/TLC) ratio (14) at school age. Impaired lung function caused by BPD appears to persist into not only childhood but also adolescence. A diminished $\mathrm{FEV}_{1} / \mathrm{FVC}$ of BPD survivors was observed in late adolescence (15). Furthermore, alterations in airway hyperresponsive, diffuse capacity, lung and chest wall mechanics, ventilation inhomogeneity and exhaled nitric oxide have been observed in infancy, preschool age and childhood (16). Yang et al. (4) then reported that adult VLBW survivors especially those with BPD had a higher incidence of airflow obstruction, gas trapping, reduced gas exchange, and increased ventilatory inhomogeneity versus controls. BPD might have negative effects continuously on lung function at adults.

However, ventilation strategies used in 1986 were quite different from now. Lung-protective ventilation (i.e., moderate PEEP, low inspiratory pressure, low tidal volume and short inspiratory time) is commonly used now in order to prevent volutrauma, barotrauma and lung inflammation which are potential risk factors to BPD. Non-invasive ventilation (i.e., nasal continuous positive airway pressure, nasal intermittent positive pressure ventilation, nasal highfrequency oscillatory ventilation etc.) is also preferred to invasive ventilation in preterm neonates as it helps increase survival rate without BPD. Non-invasive ventilation should be able to ensure maintenance of FRC, prevent cyclical reopening and closing, support fatigable ventilatory muscles and provide respiratory stimulation, thereby improving gaseous exchange. Intubation and mechanical ventilation of preterm infants remains the critical factors of subsequent BPD (17). Since Yang's study only mentioned numbers of participants and days of assisted ventilation via an endotracheal tube, we couldn't tell whether this would affect the number of participants diagnosed as BPD under different respiratory support strategy.

A better definition of BPD diagnostic criteria was addressed in 2000: oxygen need for $\geq 28$ days and at 36 weeks' postmenstrual age to identify different severity of BPD, and also to include oxygen concentration at 36 weeks' postmenstrual age to further define the severity of lung injury. Therefore, the number of preterm infants diagnosed as BPD in Yang's study may be different according to the new diagnostic criteria, which in turns affecting the results (1).

In addition to invasive mechanical ventilation exposure, surfactant deficiency in the immature lung or surfactant dysfunction due to oxidant injury and lung inflammation are contributing factors to the pathogenesis of BPD. Although late administration of exogenous surfactant did not reduce the incidence of BPD (18), early surfactant therapy helped reduce the need for aggressive ventilation strategies, thereby preventing BPD (19). It also has been recommended to use non-invasive ventilation strategies and less invasive surfactant administration/minimally invasive surfactant administration (LISA/MIST) whenever feasible for BPD prevention (20). Exogenous surfactant therapy was not used on those participants Yang's study recruited, which may affect results and cannot reflect current condition.

Despite the difference of clinical management between past and present mentioned previously, Yang's study demonstrated the long-term adverse effects of BPD on lung function and raise awareness to those survivors to keep tracking their lung function throughout life and avoid potential exacerbating risk factors. Neonatologists and respiratory therapists thus should work on reducing incidence of BPD in very preterm infants by applying and closely monitoring appropriate respiratory support strategy and medical intervention, thereby preventing short-term and long-term impacts on human health in their future life.

\section{Acknowledgments}

Funding: None.

\section{Footnote}

Conflicts of Interest: Both authors have completed the ICMJE uniform disclosure form (available at http//dx.doi. org/10.21037/tp-20-116). The authors have no conflicts of interest to declare.

Ethical Statement: The authors are accountable for all aspects of the work in ensuring that questions related to the accuracy or integrity of any part of the work are appropriately investigated and resolved.

Open Access Statement: This is an Open Access article distributed in accordance with the Creative Commons Attribution-NonCommercial-NoDerivs 4.0 International License (CC BY-NC-ND 4.0), which permits the noncommercial replication and distribution of the article with the strict proviso that no changes or edits are made and the original work is properly cited (including links to both the formal publication through the relevant DOI and the license). 
See: https://creativecommons.org/licenses/by-nc-nd/4.0/.

\section{References}

1. Bancalari E, Claure N. Definitions and diagnostic criteria for bronchopulmonary dysplasia. Semin Perinatol 2006;30:164-70.

2. Sahni M, Mowes AK. Bronchopulmonary Dysplasia. StatPearls. Treasure Island (FL): StatPearls Publishing, 2020.

3. Davidson LM, Berkelhamer SK. Bronchopulmonary dysplasia: chronic lung disease of infancy and long-term pulmonary outcomes. J Clin Med 2017;6:4.

4. Yang J, Kingsford RA, Horwood J, et al. Lung Function of Adults Born at Very Low Birth Weight. Pediatrics 2020;145:e20192359.

5. Hjalmarson O, Sandberg KL. Lung function at term reflects severity of bronchopulmonary dysplasia. J Pediatr 2005;146:86-90.

6. May C, Kennedy C, Milner AD, et al. Lung function abnormalities in infants developing bronchopulmonary dysplasia. Arch Dis Child 2011;96:1014-9.

7. Latzin $\mathrm{P}$, Roth S, Thamrin C, et al. Lung volume, breathing pattern and ventilation inhomogeneity in preterm and term infants. PloS One 2009;4:e4635.

8. Schmalisch G, Wilitzki S, Wauer R. Differences in tidal breathing between infants with chronic lung diseases and healthy controls. BMC Pediatr 2005;5:36.

9. Hofhuis W, Huysman MW, van der Wiel EC, et al. Worsening of $\mathrm{V}^{\prime}$ maxFRC in infants with chronic lung disease in the first year of life: a more favorable outcome after high-frequency oscillation ventilation. Am J Respir Crit Care Med 2002;166:1539-43.

10. Fakhoury KF, Sellers C, Smith EB, et al. Serial measurements of lung function in a cohort of young children with bronchopulmonary dysplasia. Pediatrics 2010;125:e1441-7.

Cite this article as: Chen IL, Chen HL. Lung function in adults born prematurely with bronchopulmonary dysplasia. Transl Pediatr 2020;9(3):210-212. doi: 10.21037/tp-20-116
11. Vom Hove M, Prenzel F, Uhlig HH, et al. Pulmonary outcome in former preterm, very low birth weight children with bronchopulmonary dysplasia: a case-control followup at school age. J Pediatr 2014;164:40-5.e4.

12. Filippone M, Sartor M, Zacchello F, et al. Flow limitation in infants with bronchopulmonary dysplasia and respiratory function at school age. Lancet 2003;361:753-4.

13. Hacking DF, Gibson AM, Robertson C, et al. Respiratory function at age 8-9 after extremely low birthweight or preterm birth in Victoria in 1997. Pediatr Pulmonol 2013;48:449-55.

14. Cazzato S, Ridolfi L, Bernardi F, et al. Lung function outcome at school age in very low birth weight children. Pediatr Pulmonol 2013;48:830-7.

15. Doyle LW, Faber B, Callanan C, et al. Bronchopulmonary dysplasia in very low birth weight subjects and lung function in late adolescence. Pediatrics 2006;118:108-13.

16. Vrijlandt E, Duiverman E. Pulmonary function testing in premature infants and infants with bronchopulmonary dysplasia. Eur Respir Monogr 2010;47:251-62.

17. Van Marter LJ, Allred EN, Pagano M, et al. Do clinical markers of barotrauma and oxygen toxicity explain interhospital variation in rates of chronic lung disease? Pediatrics 2000;105:1194-201.

18. Laughon M, Bose C, Moya F, et al. A pilot randomized, controlled trial of later treatment with a peptidecontaining, synthetic surfactant for the prevention of bronchopulmonary dysplasia. Pediatrics 2009;123:89-96.

19. Stevens TP, Blennow M, Myers EH, et al. Early surfactant administration with brief ventilation vs. selective surfactant and continued mechanical ventilation for preterm infants with or at risk for respiratory distress syndrome. Cochrane Database Syst Rev 2007;4:CD003063.

20. Dumpa V, Bhandari V. Surfactant, steroids and noninvasive ventilation in the prevention of BPD. Semin Perinatol 2018;42:444-52. 